\title{
Structures of Membrane Electrode Assembly Catalyst Layers for Proton Exchange Membrane Fuel Cells
}

\author{
Tzyy-Lung Leon $\mathrm{Yu}^{*}{ }^{* 1,2}$, Hsiu-Li Lin ${ }^{1,2}$, Po-Hao $\mathrm{Su}^{1}$ and Guan-Wen Wang ${ }^{1}$ \\ ${ }^{I}$ Department of Chemical Engineering \& Materials Science, ${ }^{2}$ Fuel Cells Center, Yuan Ze University, Nei-Li, Chung-Li, \\ Taoyuan 32003, Taiwan
}

\begin{abstract}
In this paper, we modify the conventional 5-layer membrane electrode assembly (MEA, in which a proton exchange membrane (PEM) is located at its center, two Pt-C-40 (Pt on carbon powder support, Pt content 40 wt.\%) catalyst layers (CLs) are located on the surfaces of the both sides of the PEM and two gas diffusion layers (GDLs) are attached next on the outer surfaces of two Pt-C-40 layers) and propose 7-layer and 9-layer MEAs by coating thin Pt-black CLs at the interfaces between the Pt-C-40 layer and the GDL and between the PEM and the Pt-C-40 layer and reducing the Pt-C-40 loading. The reduced Pt loading quantity of the Pt-C-40 layer is equal to the increased Pt loading quantity of the Pt-black layer, thus the total amount of Pt loadings in the unmodified conventional MEA and the modified MEAs are at a fixed Pt loading quantity. These modified MEAs may complicate the manufacture process. The main advantage of these 7- and 9-layer MEAs is the thinner CL thickness and thus lower CL proton transport resistance. Because of the thin Pt-black layer thickness in MEA, we avoid agglomeration of the Pt-black particles and maintain high Pt catalytic activity. We show these new CL structure MEAs have better fuel cells performance than the conventional 5-layer MEA.
\end{abstract}

Keywords: Fuel cell, membrane electrode assembly, catalyst layer, Pt-black, carbon supported Pt.

\section{INTRODUCTION}

Limitation of the fossil resource and the pollution problems have driven the researchers to search for the green energies and next generation power sources. The proton exchange membrane fuel cell (PEMFC) is currently considered as one of the best candidates for the alternative to the traditional power sources due to its high efficiency and low-pollution. However, the high cost of the cell components causes impediment to its commercialization. One of the primary contributors to the PEMFC's high cost is the catalyst, i.e. platinum $(\mathrm{Pt})$. Lots of researchers made efforts to find cheaper metals to replace the expensive Pt catalysts $[1,2]$, however, Pt catalyst is still widely used in PEMFCs due to its high catalytic activity and high stability. Thus raising the Pt catalysis efficiency and utilization is one of the important issues for the cost reduction and the commercialization of the PEMFCs.

In the past two decades, several catalyst layer (CL) structure designs and fabrication methods for the PEMFC membrane electrode assemblies (MEAs) had been reported in literature [2-13]. The most widely used MEA CL structure is shown in Fig. (1-a), which consists of a proton exchange membrane (PEM) located at the center of the MEA, two carbon powder supported $\mathrm{Pt}(\mathrm{Pt}-\mathrm{C})$ CLs located on the surfaces of the both sides of the PEM, and two gas diffusion layer (GDL, a porous carbon cloth or carbon paper) attached next on the outer surfaces of the two CLs. Usually, the CL is fabricated by mixing the Pt-C agglomerates with solubilised

*Address correspondence to this author at the Department of Chemical Engineering \& Materials Science, Yuan Ze University, Nei-Li, Chung-Li, Taoyuan 32003, Taiwan; Tel: +886-3-4638800, Ext. 2553;

Fax:+886-3-4559373; E-mail: cetlyu@saturn.yzu.edu.tw polymer electrolytes (i.e., Nafion ionomer in this study) and applying the paste to the GDL. However, up to $50 \%$ of the Pt atoms in such electrodes may be inactive [14]. Two important factors controlling the catalyst utilization in an MEA are: (1) the catalyst catalysis activity, which depends on the specific surface area of the catalyst particles and (2) the proton transport resistance in the CLs, which depends on the protons transport path length in the CLs and the ratio of the Pt particles in contact with the ionic groups of the polyelectrolyte binder (i.e., the sulfonic acid groups of Nafion resin in this study).

The Pt particles with higher surface area have higher catalysis activity. In order to raise catalyst utilization and catalysis activity, it is necessary that the Pt particles have low agglomeration in the CLs of an MEA. The Pt-Cs with a Pt content of $\sim 20-50$ wt. $\%$ are usually used for CL fabrications $[15,16]$. The advantage of using Pt-C catalysts is the reduction of nano-Pt particles agglomeration and thus increases the Pt catalytic surface area. The Pt particle sizes increase with increasing the quantity of Pt deposited on the carbon powder surfaces, and the Pt specific catalytic surface area decreases with increasing the Pt deposited quantity on the carbon supported powder surfaces [17]. The particle sizes of the carbon powders of the commercial Pt-Cs are $\sim 50-80$ $\mathrm{nm}$ [15] and the particle sizes of the Pt particles deposited on the carbon powder surfaces increase from $1.5 \mathrm{~nm}$ to $4.9 \mathrm{~nm}$ (with Pt specific surface area decreases from $185 \mathrm{~m}^{2} \mathrm{~g}^{-1}$ to 57 $\mathrm{m}^{2} \mathrm{~g}^{-1}$ ) when the amount of the Pt deposited on the carbon powder surfaces is increased from $5 \mathrm{wt} \%$ to $80 \mathrm{wt} . \%$ $[16,17]$.

In order to reduce the $\mathrm{CL}$ proton transport resistance, it is necessary that the Pt atoms are in contact with the ionic groups of the polyelectrolyte binders, i.e. the sulfonic acid 


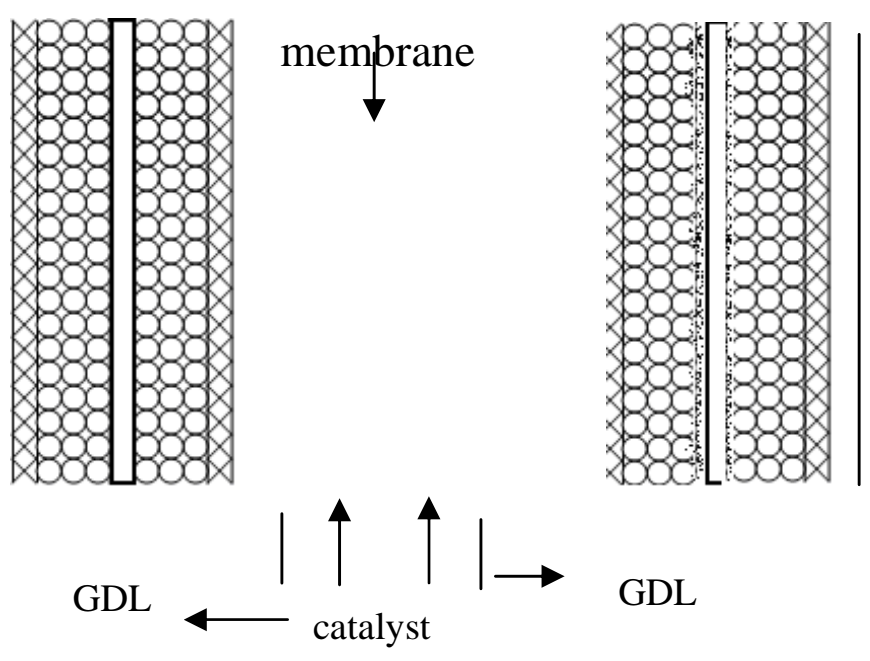

(1-a)

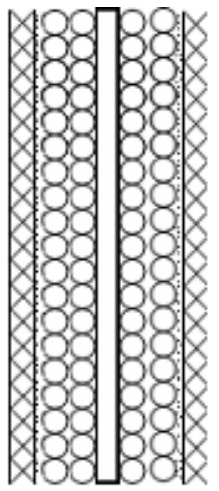

(1-b)

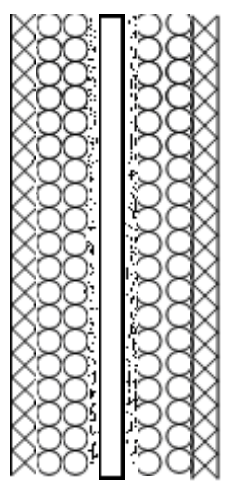

(1-c)

\section{Catalyst}

(O) $\mathrm{Pt} / \mathrm{C}$

( ) $\mathrm{Pt}$

$\longrightarrow$ membrane

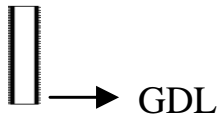

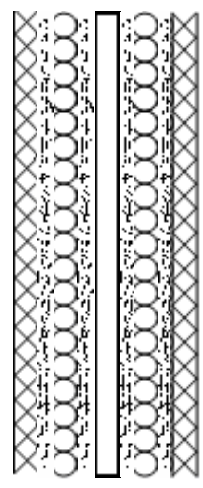

(1-d)

Fig. (1). Structures of membrane electrode assemblies. (1-a) 5-layer conventional MEA with Pt-C catalysts layer locates between membrane and GDL; (1-as) 7-layer MEA with a sputtering Pt layer locates near membrane and a Pt-C layer locates near GDL; (1-b) 7-layer MEA with a Pt-black layer locates near GDL and a Pt-C layer locates near membrane; (1-c) 7-layer MEA with a Pt-black layer locates near membrane and a Pt-C layer locates near GDL; (1-d) 9-layer MEA with Pt-black layers locate both near the GDL and the membrane and a Pt-C layer locates between two Pt-black layers. The Pt-C layers in structures (1-b), (1-c), and (1-d) are thinner than the Pt-C layer in structure (1-a). The $\mathrm{Pt}-\mathrm{C}$ catalyst layer in structure (1-as) has same thickness as that in structure (1-a). Catalysts: $(\mathrm{O}) \mathrm{Pt}-\mathrm{C}(50 \sim 100 \mathrm{~nm}) ;(\cdot) \mathrm{Pt}(2 \sim 5 \mathrm{~nm})$.

groups of Nafion, which provide travelling paths for the protons generated from the electrochemical reaction on the Pt particle surfaces. The catalytic reaction zone may be extended by increasing the amount of the polyelectrolyte throughout the CL, but too much polyelectrolyte coverage on the surfaces of the $\mathrm{Pt}$ particles may retard the fuel and oxidant gases to reach the $\mathrm{Pt}$ particles [4,5]. Thus an optimum ratio of $[\mathrm{Pt}] /[$ polyelectrolyte binder] is necessary for a $C L$ with a high proton transport efficiency. The other factor controlling the CL proton transport efficiency is the
CL thickness. Increasing CL thickness increases the CL proton transport path length, and leads to higher proton transport resistance. In order to obtain a PEMF with a high Pt catalysis and utilization, one should increase the catalyst particle surface area (i.e., reduce the $\mathrm{Pt}$ particle sizes and particle agglomerations) and reduce the CL thickness under an optimum $[\mathrm{Pt}] /[$ polyelectrolyte binder] ratio in the MEA.

At a fixed Pt-loading, fabricating a high Pt content Pt-C catalysts in a CL causes increases both in the Pt particle sizes and the CL thickness (because of the low content of large 
carbon particles), and leads to the reductions of the $\mathrm{Pt}$ catalysis activity and the $\mathrm{CL}$ proton transport resistance. However, the fabrication of the low Pt content Pt-C catalysts causes decrements both in the Pt particle sizes and the CL thickness (because of the high content of the large carbon particles), and leads to the increases both in the Pt catalytic activity and the CL proton transport resistance. Thus, how to obtain "a MEA with high Pt catalysis activity and low proton transport resistance $C L$ " is one of the important issues of CL structure design and fabrication. Most of the researchers fabricate MEAs using the Fig. (1-a) CL structure with Pt-C40 (Pt content 40 wt.\%, particle sizes $\sim 2.9 \mathrm{~nm}$, specific surface area $\sim 110 \mathrm{~m}^{2} \mathrm{~g}^{-1}$ ) $\sim$ Pt-C-50 (Pt content $50 \mathrm{wt} . \%$, particle sizes $\sim 3.3 \mathrm{~nm}$, specific surface area $\sim 86 \mathrm{~m}^{2} \mathrm{~g}^{-1}$ ) catalysts. At a fixed Pt loading, the use of Pt-C-40 Pt-C-50 catalysts containing $40-50 \mathrm{wt} . \% \mathrm{Pt}$ has a medium Pt catalytic surface area and a medium CL thickness, and thus an optimum PEMFC performance.

An improvement of fuel cell power output by modifying CL structure design had been reported in literature and is shown in Fig. (1-as). Its structure is similar to Fig. (1-a), but with an additional sputtered $\mathrm{Pt}$ thin film located between the PEM and the Pt-C-20 (Pt content 20 wt.\%) layer $[8,18,19]$. These authors suggested that sputtering an additional Pt thin film with a Pt loading of $0.05 \mathrm{mg} \mathrm{cm}^{-2}$ at the interface between the Pt-C-20 layer and PEM (the total Pt loading was $0.45 \mathrm{mg} \mathrm{cm}^{-2}$ ) could enhance the fuel cell output power higher than the Fig. (1-a) MEA which consisted of only one Pt-C CL with a Pt loading of $0.40 \mathrm{mg} \mathrm{cm}$. One of the reasons of the higher power output of Fig. (1-as) than that of Fig. (1-a) could be due to the higher total Pt loading of Fig. (1-as) than the Fig. (1-a). The main disadvantage of the CL design of Fig. (1-as) is the cost increase by sputtering an additional Pt thin film in the Fig. (1-a) design.

In this paper, we modify the Fig. (1-a) MEA structure and fabricate 7-layer (Fig. 1-b, -c) and 9-layer (Fig. 1-d) MEAs by coating thin Pt-black (particles sizes of $\sim 5.5 \mathrm{~nm}$ ) catalyst layers at the interfaces between the Pt-C-40 layer and GDL and between the PEM and Pt-C-40 layer and reducing the $\mathrm{Pt}-\mathrm{C}$ catalyst $(\mathrm{Pt}$ content $\sim 40 \mathrm{wt} \%$ and $\mathrm{Pt}$ particles sizes of $\sim 2.9 \mathrm{~nm}$ ) loading. The reduced amount of Pt loading of the Pt-C-40 layer is equal to the increased amount of Pt loading of the Pt-black layer, thus the total amount of Pt loadings of the unmodified Fig. (1-a) MEA and the modified Fig. (1-b-d) MEAs are at a fixed Pt loading quantity. The main purpose of this study is to reduce the CL thickness by replacing part of large Pt-C-40 particles layer with thin layers of small Pt-black particles and thus reduce the CL proton transport resistance. Since the Pt-black layer is thin in thickness, few Pt-black particles aggregate. Using Fig. (1-b-d) structure designs, we reduce CL proton transport resistance and maintain high $\mathrm{Pt}$ catalysis activity and thus improve the PEMFC performance.

Yang et al. [20] reported modified MEA structures similar to those of Fig. (1-b, -d). Instead of using Pt-black (Pt content $100 \mathrm{wt} . \% \mathrm{Pt}$ ), they fabricated Pt-C-80 (Pt content 80 wt.\%) thin layers at the at the interfaces between the PtC-40 layer and the GDL and between the PEM and the Pt-C40 layer and reducing the Pt-C-40 loading. Thus in Yang el al work, the Pt-black thin layers of Fig. (1-b-d) were changed with Pt-C-80 thin layers. They showed better fuel cell performances of their modified MEAs than the conventional Fig. (1-a) MEA. However, the CL thickness of Yang et al. MEAs is thicker than that of the present work, because the Pt-C- 80 particles contain large carbon powder support particles.

\section{EXPERIMENTAL}

\subsection{Preparation of Nafion PEMFC MEAs and PEMFC Single Cell Test}

\subsubsection{Materials}

The Nafion solution (Du Pont Co.) was a $5 \mathrm{wt} \%$ Nafion $(\mathrm{EW}=1100)$ diluted in a mixture solvent containing water, 2propanol, methanol, and unspecified ethers [21]. The PEM was Nafion-212 (thickness $50 \sim \mu \mathrm{m}, \mathrm{Du}$ Pont Co) [22]. The gas diffusion layer (GDL) was a carbon paper (SGL-31BC, SGL Co, Germany). The Pt-black (particles sizes around $\sim 5.5 \mathrm{~nm}$ ) and $\mathrm{Pt}-\mathrm{C}$ (Pt content $40 \mathrm{wt} \%$ ) catalysts were purchased from E-TEK Co.

\subsubsection{Preparation of PEMFC Membrane Electrode Assembly (MEA)}

Before MEA preparation, the Nafion-212 membrane was boiled at $85^{\circ} \mathrm{C}$ in $5 \mathrm{wt} \% \mathrm{H}_{2} \mathrm{O}_{2}$ aqueous solution for $1 \mathrm{~h}$, followed by boiling at $85^{\circ} \mathrm{C}$ for $1 \mathrm{~h}$ in distilled water. After that the membrane was boiled in $0.5 \mathrm{M} \mathrm{H}_{2} \mathrm{SO}_{4}$ solution for 1 $\mathrm{h}$, and subsequently boiled at $85^{\circ} \mathrm{C}$ in distilled water for 15 min. The Pt-black and Pt-C catalyst pastes were prepared by two steps. In the first mixing step, Pt-C (or Pt-black) powder was mechanically stirred for $30 \mathrm{~min}$ in isopropanol/water $(1 / 9 \mathrm{~g} / \mathrm{g})$ solvent to give a homogeneous mixture. Subsequently, in the second step, Nafion solution was added into the mixture and stirred by ultrasound. The MEAs were prepared by brushing the Pt-black and Pt-C catalyst pastes layer by layer upon GDL and dried in air at $\sim 80^{\circ} \mathrm{C}$ according to the structure designs shown in Fig. (1) and subsequently dried in vacuum at $\sim 80^{\circ} \mathrm{C}$ for $30 \mathrm{~min}$. The final wt ratios of Pt-black/Nafion and Pt-C/Nafion on GDL were 3/1 and 2/1, respectively. The Nafion membrane was sandwiched between anode and cathode electrodes and hot pressed at $135^{\circ} \mathrm{C}$ with $50 \mathrm{~kg} / \mathrm{cm}^{2}$ for $30 \mathrm{sec}$ and followed with 100 $\mathrm{kg} / \mathrm{cm}^{2}$ for $1 \mathrm{~min}$. The active area of MEA was $5 \times 5 \mathrm{~cm}^{2}$. Eleven MEAs were prepared in the present work. The structure designs and Pt-black and Pt-C loadings of MEAs are summarized in Tables $\mathbf{1 , 4}$, and 7. In Tables 1, 4, and 7, the last letter of sample designations indicates the MEA structure, which is same as the structures designations shown in Fig. (1). In Tables 1, 4, and $\mathbf{7}$ the membrane is assumed to be located in the middle, i.e. between anode and cathode, and the loading of each catalyst layer on both sides of membrane is listed sequentially from membrane in the middle to the outside layers according to the MEA structure.

\subsubsection{PEMFC Single Cell Performance Test}

The performances of PEMFC single cells were tested at $80^{\circ} \mathrm{C}$ using a Globe Tech Computer Cell GT testing system (Electrochem Inc). The anode input $\mathrm{H}_{2}$ and the cathode input $\mathrm{O}_{2}$ flow rates were $200 \mathrm{ml} \mathrm{min}{ }^{-1}$. Before $i-V$ curve was collected, the cell was activated at $80^{\circ} \mathrm{C}$ and $0.5 \mathrm{~V}$ for $3 \mathrm{~h}$ to enhance humidification and activation of MEA. $i-V$ curves were obtained by measuring the current density $i$ with step 
Table 1. The Catalysts Loadings of Structure-a and Structure-b MEAs. Total Pt Loading is $0.5 \mathrm{mg} \mathrm{cm}^{-2}$ at Anode and $1.0 \mathrm{mg} \mathrm{cm}$ at Cathode

\begin{tabular}{|c|c|c|c|c|c|c|c|}
\hline \multirow{2}{*}{ MEA\# } & \multicolumn{3}{|c|}{ Anode (mg cm-2 } & \multicolumn{3}{c|}{ Cathode (mg cm-2 } & \multirow{2}{*}{ MEA Thickness $(\mu$ m) } \\
\cline { 2 - 9 } & Pt Near GDL & Pt-C (40 wt.\%) & Pt Near Membr & Pt Near Membr & Pt-C (40 wt.\%) & Pt Near GDL & \\
\hline \hline N212-a & & 1.25 & & & 2.5 & & 461 \\
\hline N212-1b & 0.05 & 1.125 & --- & --- & 2.375 & 0.05 & 447 \\
\hline N212-2b & 0.1 & 1.0 & ---- & --- & 2.25 & 0.1 & 435 \\
\hline N212-3b & 0.2 & 0.75 & --- & --- & 2.0 & 0.2 & 413 \\
\hline
\end{tabular}

decrement of voltage $V$ by an interval of $0.05 \mathrm{~V}$. The time was held $20 \mathrm{sec}$ for each measurement.

\section{RESULTS AND DISCUSSIONS}

\subsection{Structure-b MEA}

In this section, the structure-b MEAs (i.e. N212-1b, N$212-2 b$, and N-212-3b) were prepared by replacing part of Pt-C particles in Pt-C layers of structure-a MEA with thin layers of various Pt-black loadings. The fuel cells performances of these MEAs were investigated. A structurea MEA (i.e. N-212-a) with a same Pt loading as those of structure-b MEAs was also prepared for a reference. The catalysts loadings and MEA thickness of N212-a, N212-1b, $\mathrm{N} 212-2 \mathrm{~b}$, and N212-3b are summarized in Table 1.

Figs. $(2,3)$ show voltage $V$ versus current density $i$ and power density $(P D)$ versus $i$ curves, respectively, for N212a, N212-1b, N212-2b, and N212-3b. Table 2 summarizes the open circuit voltage (OCV), maximum power density $\left(P D_{\max }\right)$, and resistances $R$ at $i=200,400,800$, and $1000 \mathrm{~mA}$ $\mathrm{cm}^{-2}$ of these MEAs. The resistances of MEAs were

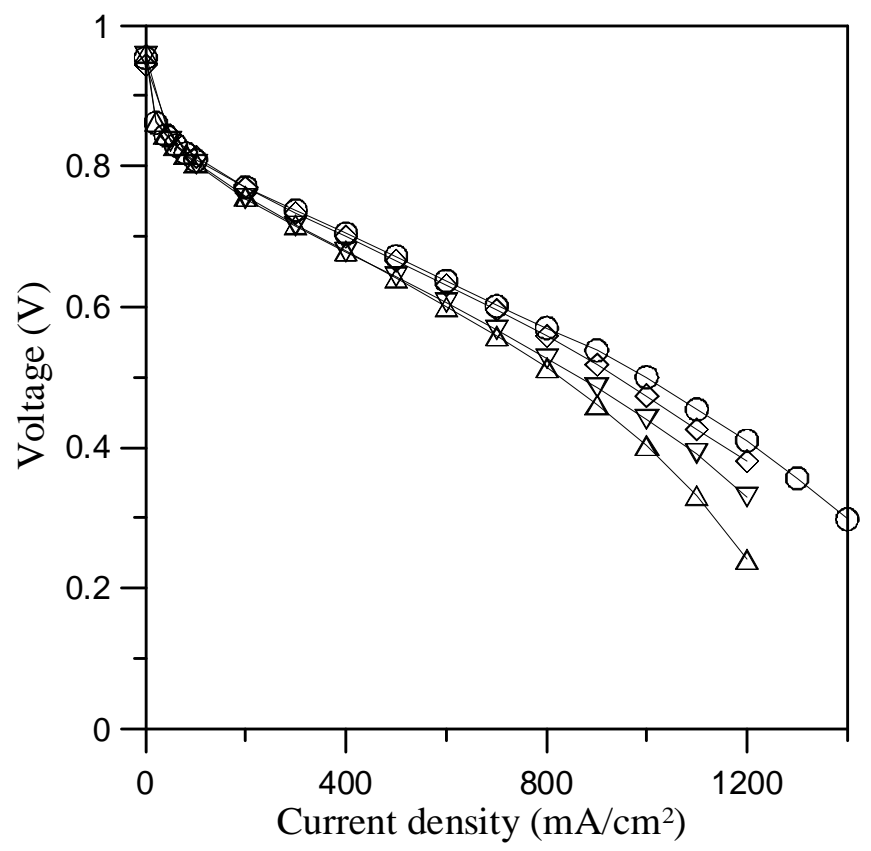

Fig. (2). $i-\mathrm{V}$ curves of structure-a and structure-b single cells operated at $80^{\circ} \mathrm{C}$ with both $\mathrm{H}_{2}$ and $\mathrm{O}_{2}$ flow rates of $200 \mathrm{ml} / \mathrm{min}$. ( $\left.\nabla\right)$

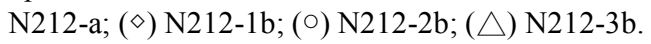

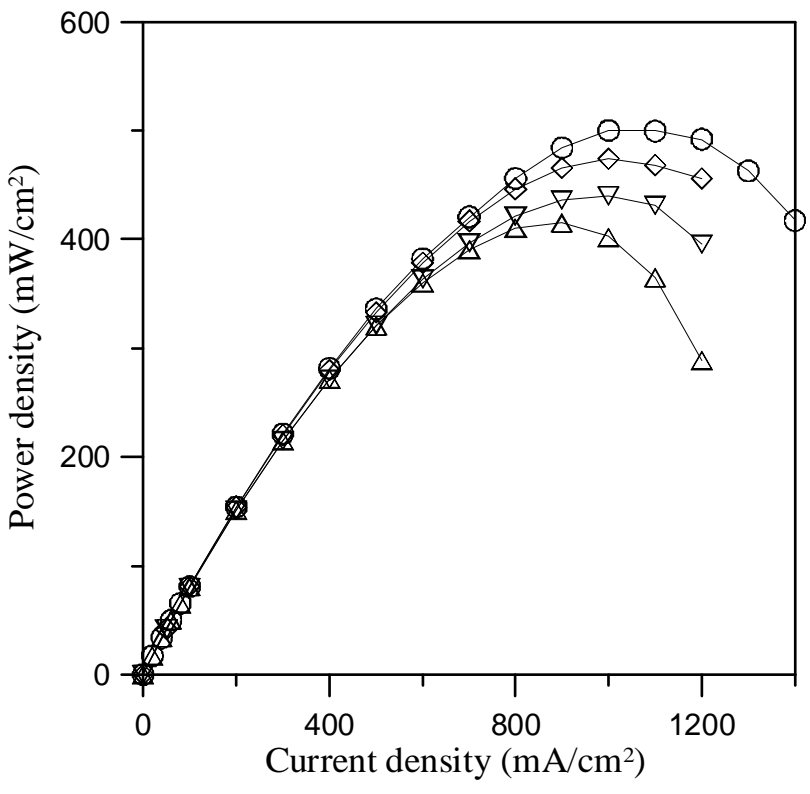

Fig. (3). $i$-PD curves of structure-a and structure-b single cells operated at $80^{\circ} \mathrm{C}$ with both $\mathrm{H}_{2}$ and $\mathrm{O}_{2}$ flow rates of $200 \mathrm{ml} / \mathrm{min} .(\nabla)$

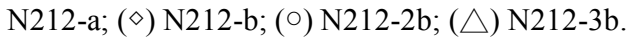

measured by using a current-interrupt method during fuel cell performance test [23]. The data of Figs. $(\mathbf{2}, \mathbf{3})$ show that $\mathrm{N} 212-1 \mathrm{~b}$ and $\mathrm{N} 212-2 \mathrm{~b}$ have better fuel cell performance than N212-a, indicating replacing $10 \sim 20$ wt.\% of Pt from Pt-C (40 wt.\% Pt) with Pt-black at anode and replacing $5 \sim 10$ wt.\% of Pt from Pt-C (40 wt.\% Pt) with Pt-black at cathode and coating the Pt-black layer at the interface between Pt-C layer and GDL can improve fuel cell performance. These results also show that replacing $20 \mathrm{wt} . \%$ of $\mathrm{Pt}$ from $\mathrm{Pt}-\mathrm{C}$ (40 wt.\% Pt) with Pt-black at anode and replacing $10 \mathrm{wt} . \%$ of $\mathrm{Pt}$ from Pt-C (40 wt.\% Pt) with Pt-black at cathode (i.e. MEA $\mathrm{N} 212-2 \mathrm{~b}$ ) has the best fuel cell performance. However, as the replacement of $\mathrm{Pt}$ from $\mathrm{Pt}-\mathrm{C}$ (40 wt.\% Pt) with Pt-black is increased up to $40 \mathrm{wt} \%$ at anode and $20 \mathrm{wt} \%$ at cathode (i.e. MEA N212-3b) the fuel cell performance is similar to that of N212-a when $i<400 \mathrm{~mA} \mathrm{~cm}^{-2}$ and slightly worse than that of $\mathrm{N} 212$-a when $i$ is higher than $400 \mathrm{~mA} \mathrm{~cm}^{-2}$.

Since these four MEAs have same proton exchange membrane and same amount of total Pt loading, the difference in fuel cell output power of these four MEAs comes from the difference in catalyst layer thickness and Ptblack loading quantity. The reason for better fuel cell performances of N212-1b and N212-2b than N212-a can be attributed to the lower proton transport resistance (or shorter 
Table 2. OCV, $P_{\max }$, and $R$ Values of Structure-a and Structure-b MEAs

\begin{tabular}{|c|c|c|c|c|}
\hline MEA \# & N212-a & N212-1b & $\mathbf{N} 212-2 b$ & N212-3b \\
\hline $\mathrm{OCV}(\mathrm{V})$ & 0.96 & 0.94 & 0.95 & 0.96 \\
\hline$R\left(\Omega \mathrm{cm}^{2}\right)$ at $i=200 \mathrm{~mA} \mathrm{~cm}^{-2}$ & 0.134 & 0.111 & 0.108 & 0.136 \\
\hline$R\left(\Omega \mathrm{cm}^{2}\right)$ at $i=400 \mathrm{~mA} \mathrm{~cm}^{-2}$ & 0.130 & 0.111 & 0.102 & 0.132 \\
\hline$R\left(\Omega \mathrm{cm}^{2}\right)$ at $i=1000 \mathrm{~mA} \mathrm{~cm}^{-2}$ & 0.138 & 0.115 & 0.110 & 0.137 \\
\hline
\end{tabular}

proton transport path length) due to lower catalyst layer thickness. Table 1 shows the thicknesses of N212-1b and $\mathrm{N} 212-2 \mathrm{~b}$ are lower than that of N212-a, and Table 2 shows $\mathrm{N} 212-1 \mathrm{~b}$ and N212-2b have lower resistance $R$ than N212-a. Fig. (2) also shows that when $i$ is between $200 \mathrm{~mA} / \mathrm{cm}^{2}$ and $800 \mathrm{~mA} / \mathrm{cm}^{2}, \mathrm{~N} 212-1 \mathrm{~b}$ and $\mathrm{N} 212-2 \mathrm{~b}$ have lower $V$ versus $i$ negative slopes than $\mathrm{N} 212-\mathrm{a}$, indicating lower resistance of $\mathrm{N} 212-1 b$ and N212-2b than N212-a. The behavior of lower negative slopes of $V$ versus $i$ curves of N212-1b and N212$2 \mathrm{~b}$ than $\mathrm{N} 212$-a is in consistent with the $R$ values shown in Table 2 .

The worse fuel cell performance of N212-3b than N212-a can be attributed to the agglomeration of Pt-black particles in Pt-black layer because of thick $\mathrm{Pt}$ black layer. The agglomeration of Pt-black particles causes some of the $\mathrm{Pt}$ particles to be buried inside the agglomeration particles. The Pt particles buried inside the agglomerations might not be in contact with Nafion resin and not facilitate for proton transport in catalyst layer. The other reason for the lower fuel cell performance of N212-3b than N212-a can be attributed the blockage of fuel $\mathrm{H}_{2}$ and oxidant $\mathrm{O}_{2}$ flows, because of cumulating of lots of small nano-Pt particles on GDL. Table 2 shows N212-3b has $R$ similar to that of N212-a. But, Fig. (2) shows that when $i$ is higher than $400 \mathrm{~mA} \mathrm{~cm}$, N212-3b has lower $V$ than N212-a. The lower $V$ of N212-3b at $i>400 \mathrm{~mA} \mathrm{~cm}^{-2}$ is a behavior of concentration polarization due to blockage of fuel flow [24].

As mentioned in the introduction section, two important factors influencing the efficiency of catalyst layers are: (1) the specific surface area $a_{c}$ of catalysts particles and (2) the resistance $R$ of proton transference in the catalyst layers of anode and cathode. The information of specific surface area $a_{c}$ of catalysts can be obtained by analyzing $i$-V curve using Tafel Eq. 1 [24].

$\Delta \mathrm{V}_{\text {act }}=\mathrm{a}+\mathrm{b} \log i$

In Eq. 1, the coefficient " $a$ " is:

$\mathrm{a}=-2.303 \mathrm{RT} \log i_{o} / \alpha \mathrm{F}$

with $\alpha$ is the electron transfer coefficient and $\alpha=0.2 \sim 2.0$ for a hydrogen fuel cell electrode [25], F the Faraday constant, $i_{o} \sim a_{c} L_{c}$ the exchange current density, in which $a_{c}$ is the specific surface area of catalyst, and $L_{c}$ the catalyst loading per unit area of MEA. The coefficient $b$ in Eq. 1 is:

$\mathrm{b}=2.303 \mathrm{RT} / \alpha \mathrm{F}$

The $\Delta V_{a c t}$ in Eq. 1 is the activation loss and $\Delta V_{a c t}$ is related to the cell potential $E_{\text {cell }}$ and resistance $R$ of a MEA by Eq. 4 .
$\Delta \mathrm{V}_{\mathrm{act}}=\mathrm{E}_{\mathrm{r}}-\mathrm{E}_{\text {cell }}-i \mathrm{R}$

where $E_{r}$ is the reversible cell potential and $E_{r}=1.18 \mathrm{~V}$ for PEMFC operated at $80^{\circ} \mathrm{C}[25]$.

Fig. (4) shows the plots of Eq. 1 for N212-a, N212-1b, $\mathrm{N} 212-2 \mathrm{~b}$, and N212-3b. The slope of the plot is Tafel slope $b$ and intercept is $a$. Using Eq. 3, we calculated $\alpha$ from $b$. And using Eq. 2, we calculated $i_{o}$ from $a$. The values of $a, b, i_{o}$, and $\alpha$ are listed in Table 3 . Table 3 shows that N212-a has highest $i_{o}$ and N212-3b has lowest $i_{o}$ in these four MEAs. Since all the four MEAs had same catalyst loading $L_{c}$, the results of Table 3 suggest that N212-a with catalyst layers consisting only of $\mathrm{Pt}-\mathrm{C}$ has the highest catalyst specific surface area $a_{c}$ and thus highest catalyst activity. Table 3 also shows N212-3b has lowest $i_{o}$, i.e. lowest catalyst activity, in these four MEAs. It is obvious that coating large quantity of Pt-black particles on GDL surface results in aggregations of Pt-black particles and reduction of Pt specific surface area $a_{c}$, thus N212-3b has a lowest $i_{o}$ value. However, the Pt particles of Pt-C are well dispersed on the surface of carbon powders and N212-a has a highest Pt specific surface area $a_{c}$ and a highest $i_{o}$ value in these four MEAs.

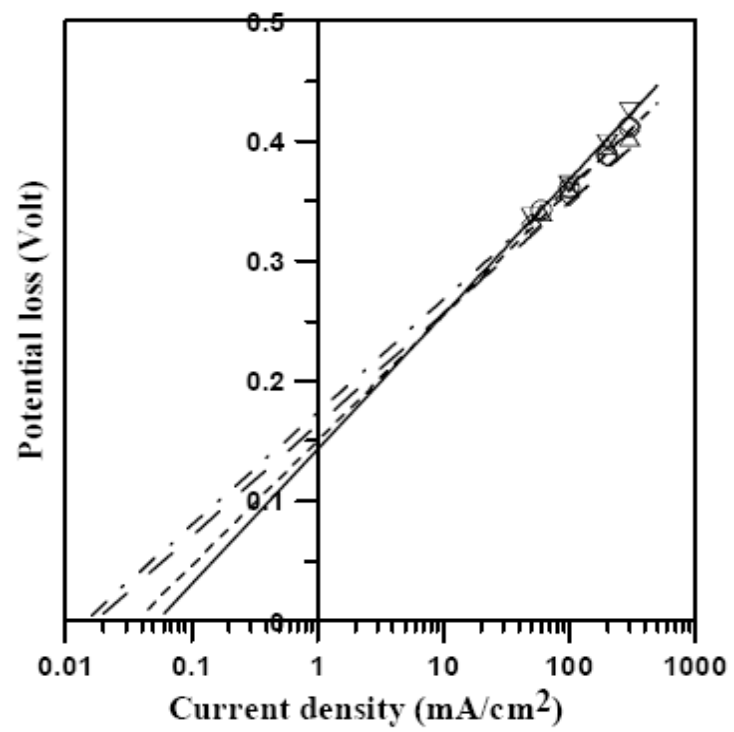

Fig. (4). Plots of activation loss potential $\Delta \mathrm{V}_{\text {act }}$ versus logi (Eq. 1) of structure-a and structure-b MEAs. ( $\nabla---)$ N212-a; ( $\diamond-------)$

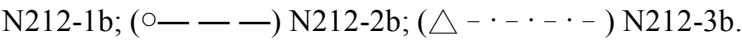

\subsection{Structure-c MEA}

In this section, two structure-c MEAs, i.e. N212-1c and $\mathrm{N}-212-2 \mathrm{c}$, with structure-c catalyst layer design shown in 
Fig. (1c) were prepared and their fuel cell performances were investigated and compared with that of N212-a. The catalysts loadings and MEA thicknesses of N212-1c and $\mathrm{N} 212-2 \mathrm{c}$ are summarized in Table 4 . The Pt-C and Pt-black catalysts loadings of N212-1c and N212-2c are same as those of N212-1b and N212-2b, respectively. The difference between these two series of MEAs is the location of Pt-black layer. In structure-b MEA, the Pt-black layer is located at the interface between Pt-C layer and GDL. However in structure-c MEA, the Pt-black layer is located at the interface between Pt-C layer and membrane. Table $\mathbf{4}$ also shows that the Pt-black loading at cathode is same as that at anode, though the total $\mathrm{Pt}$ loading at cathode is twice of that at anode.

Table 3. $a, b$, and $i_{o}$ Values (Eq. 1) of Structure-a and Structure-b MEAs Obtained from Fig. (4)

\begin{tabular}{|c|c|c|c|c|}
\hline MEA\# & $\mathbf{b}\left(\mathbf{m} \boldsymbol{\Omega} \mathbf{~ c m}^{2}\right)$ & $\boldsymbol{\alpha}$ & $\mathbf{a}(\mathbf{V})$ & $\boldsymbol{i}_{o}\left(\mathbf{m A} \mathbf{~ c m}^{-2}\right)$ \\
\hline \hline $\mathrm{N} 212-\mathrm{a}$ & 0.1127 & 0.6 & 0.1433 & 0.054 \\
\hline $\mathrm{N} 212-1 \mathrm{~b}$ & 0.1046 & 0.7 & 0.1497 & 0.037 \\
\hline $\mathrm{N} 212-2 \mathrm{~b}$ & 0.0972 & 0.7 & 0.1682 & 0.019 \\
\hline $\mathrm{N} 212-3 \mathrm{~b}$ & 0.0941 & 0.7 & 0.1738 & 0.014 \\
\hline
\end{tabular}

Figs. $(5, \mathbf{6})$ show the cell potential $V$ versus $i$ and power density $P D$ versus $i$ curves, respectively, for N212-a, N212$1 \mathrm{c}$, and $\mathrm{N} 212-2 \mathrm{c}$. Table 5 summarizes the $\mathrm{OCV}, \mathrm{PD}_{\max }$, and $R$ values of theses MEAs. The data of Figs. $(5,6)$ show that $\mathrm{N} 212-1 \mathrm{c}$ and N212-2c have better fuel cell performance than N212-a, indicating replacing $10 \sim 20 \mathrm{wt} . \%$ of Pt from Pt-C (40 wt.\% Pt) layer with Pt-black at anode and replacing 5 10 wt.\% of Pt from Pt-C (40 wt.\% Pt) layer with Pt-black at cathode and coating the Pt-black film at the interface between membrane and Pt-C layer can improve the fuel cell performance. These results also show that replacing $20 \mathrm{wt} . \%$ of Pt from Pt-C (40 wt.\% Pt) layer with Pt-black at anode and replacing $10 \mathrm{wt} . \%$ of Pt from Pt-C (40 wt.\% Pt) layer with Pt-black at cathode (i.e. N212-2c MEA) has best fuel cell performance in these MEAs.

Table 5 shows $R$ data of N212-1c and N212-2c at $i=200$, 400,800 , and $1000 \mathrm{~mA} \mathrm{~cm}{ }^{-2}$. Comparing $R$ data of N212-a (Table 2) with those of N212-1c and N212-2c (Table 5), we found that $\mathrm{N} 212-1 \mathrm{c}$ and $\mathrm{N} 212-2 \mathrm{c}$ had lower resistance $R$ than $\mathrm{N} 212$-a at $i=200,400,800$, and $1000 \mathrm{~mA} \mathrm{~cm}{ }^{-2}$. We also found the thicknesses of N212-1c and N212-2c (Table 4) were lower than that of N212-a (Table 1). Fig. (7) shows the plots of Eq. 1 for N212-a, N212-1c, and N212-2c. The values of $a, b, i_{o}$, and $\alpha$ of N212-1c and N212-2c calculated from the plots of Fig. (7) are listed in Table 6. From Tables 3

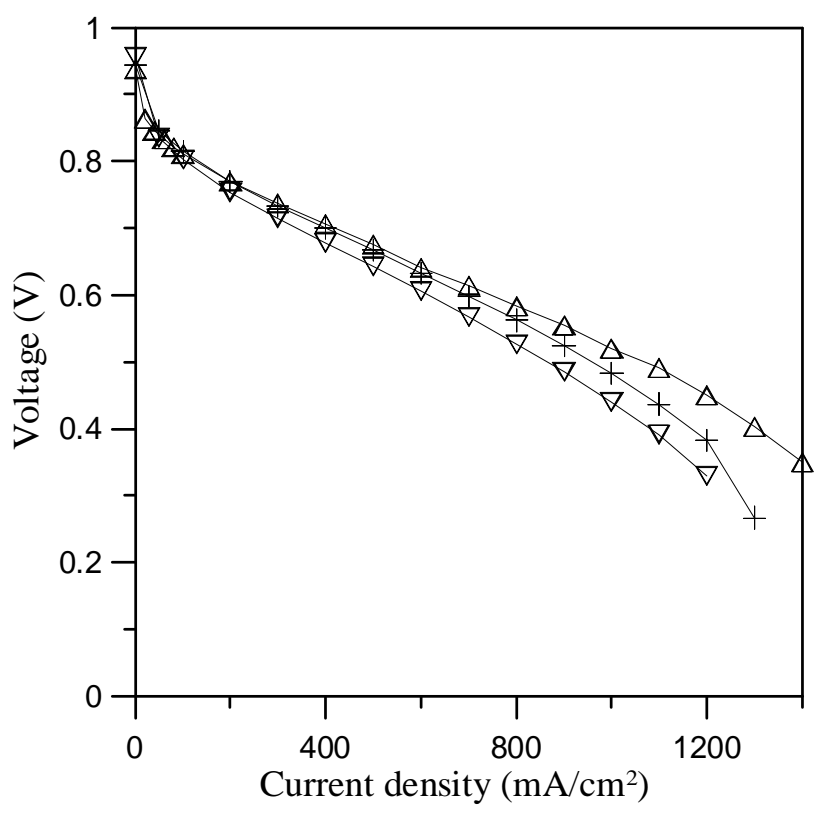

Fig. (5). $i-\mathrm{V}$ curves of structure-a and structure-c single cells operated at $80^{\circ} \mathrm{C}$ with both $\mathrm{H}_{2}$ and $\mathrm{O}_{2}$ flow rates of $200 \mathrm{ml} \mathrm{min}^{-1}$. ( $\nabla) \mathrm{N} 212-\mathrm{a} ;(+) \mathrm{N} 212-1 \mathrm{c} ;\left({ }^{\triangle}\right) \mathrm{N} 212-2 \mathrm{c}$.

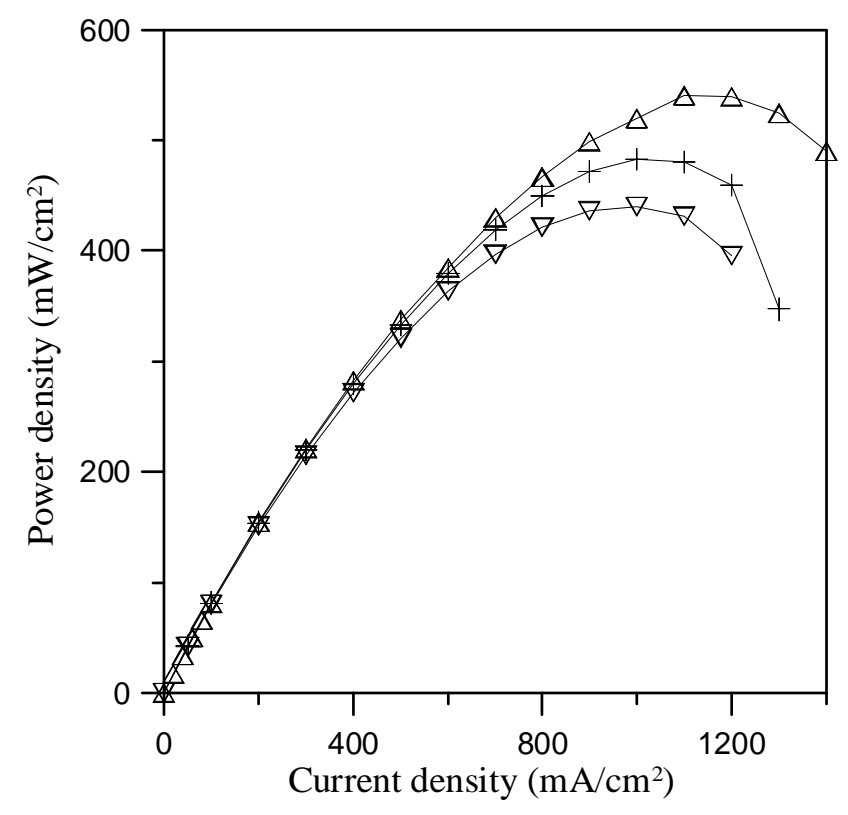

Fig. (6). $i$-PD curves of structure-a and structure-c single cells operated at $80^{\circ} \mathrm{C}$ with both $\mathrm{H}_{2}$ and $\mathrm{O}_{2}$ flow rates of $200 \mathrm{ml} \mathrm{min}$. ( $\nabla) \mathrm{N} 212-\mathrm{a} ;(+) \mathrm{N} 212-1 \mathrm{c} ;\left({ }^{\triangle}\right) \mathrm{N} 212-2 \mathrm{c}$.

and 6, we found that N212-a had higher $i_{o}$ than N212-1c and $\mathrm{N} 212-2 \mathrm{c}$, and $\mathrm{N} 212-2 \mathrm{c}$ had lowest $i_{o}$ in these three

Table 4. The Catalysts Loadings of Structure-c MEAs. Total Pt Loading is $0.5 \mathrm{mg} \mathrm{cm}^{-2}$ at Anode and $1.0 \mathrm{mg} \mathrm{cm}^{-2}$ at Cathode

\begin{tabular}{|c|c|c|c|c|c|c|c|}
\hline \multirow{2}{*}{ MEA\# } & \multicolumn{3}{|c|}{ Anode (mg cm $\left.{ }^{-2}\right)$} & \multicolumn{3}{c|}{ Cathode (mg cm $\left.{ }^{-2}\right)$} & \multirow{2}{*}{ MEA Thickness $(\mu$ m) } \\
\cline { 2 - 8 } & Pt Near GDL & Pt-C (40 wt\% Pt) & Pt Near Membr & Pt Near Membr & Pt-C (40 wt\% Pt) & Pt Near GDL \\
\hline \hline N212-1c & --- & 1.125 & 0.05 & 0.05 & 2.375 & -- & 454 \\
\hline N212-2c & --- & 1.0 & 0.1 & 0.1 & 2.25 & -- & 440 \\
\hline
\end{tabular}


MEAs, indicating the catalysts of N212-a had highest specific area $a_{c}$ and catalysts of N212-2c had lowest specific area $a_{c}$. These $R$ and $i_{o}$ results are similar to those of N212-a with N212-1b and N212-2b. Since MEAs N212-a, N212-1c, and N212-2c have same proton exchange membrane and same amount of total Pt loading, we may also attribute the better fuel cell performance of N212-1c and N212-2c than N212-a to the lower catalyst layer thickness (or shorter proton transport path length) of N212-1c and N212-2c than N212-a, which leads to lower proton transport resistance of N212-1c and N212-2c than N212-a.

Table 5. OCV, $P_{\max }$, and $R$ Values of Structure-c MEAs

\begin{tabular}{|c|c|c|}
\hline MEA \# & N212-1c & N212-2c \\
\hline OCV (V) & 0.94 & 0.94 \\
\hline $\mathrm{PD}_{\max }\left(\mathrm{mW} \mathrm{cm} \mathrm{cm}^{-2}\right)$ & 490 & 550 \\
\hline$R\left(\Omega \mathrm{cm}^{2}\right)$ at $i=200 \mathrm{~mA} \mathrm{~cm}-2$ & 0.121 & 0.110 \\
\hline$R\left(\Omega \mathrm{cm}^{2}\right)$ at $i=400 \mathrm{~mA} \mathrm{~cm}-2$ & 0.114 & 0.103 \\
\hline$R\left(\Omega \mathrm{cm}^{2}\right)$ at $i=800 \mathrm{~mA} \mathrm{~cm}{ }^{-2}$ & 0.116 & 0.107 \\
\hline$R\left(\Omega \mathrm{cm}^{2}\right)$ at $i=1000 \mathrm{~mA} \mathrm{~cm}^{-2}$ & 0.122 & 0.111 \\
\hline
\end{tabular}

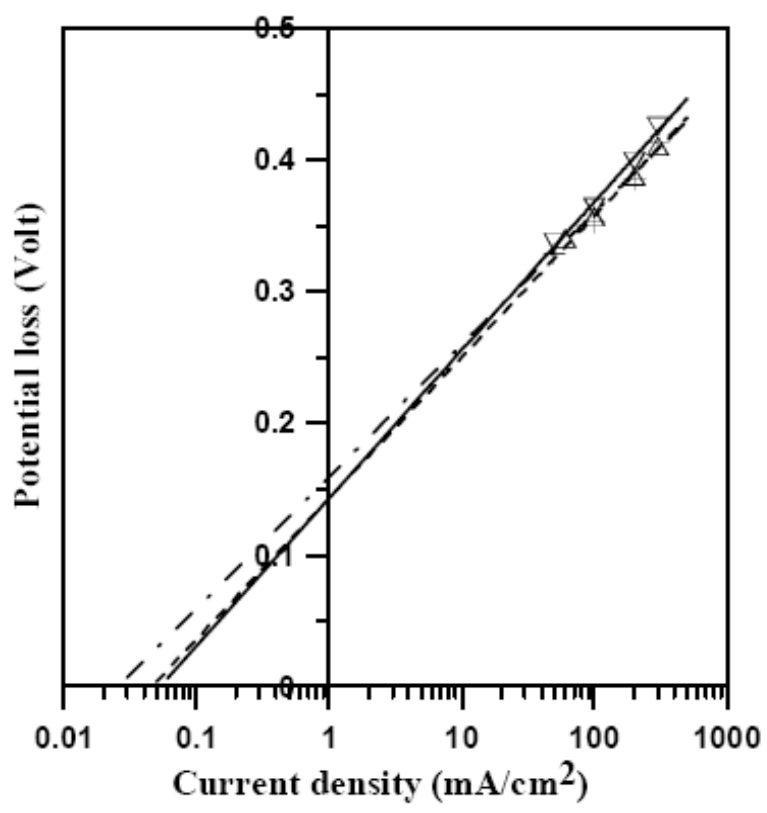

Fig. (7). Plots of activation loss potential $\Delta \mathrm{V}_{\text {act }}$ versus $\log i$ (Eq. 1) of structure-a and structure-c MEAs. ( $\nabla---)$ N212-a; (+--------) $\mathrm{N} 212-1 \mathrm{c} ;(\Delta-\cdot-\cdot-\cdot-) \mathrm{N} 212-2 \mathrm{c}$.

\subsection{Structure-d MEA}

In this section, MEAs with structure-d catalyst layer design shown in Fig. (1d) were prepared and their fuel cell performances were compared with that of N212-a. Two structure-d MEAs were prepared, i.e. N212-1d and N212-2d. The catalysts loadings and MEA thicknesses of N212-1d and N212-2d are summarized in Table 7. The Pt-C and Pt-black catalysts loadings of N212-1d (Table 7) are same as those of N212-2b (Table 1), and N212-2c (Table 4), and the Pt-C and Pt-black catalysts loadings of N212-2d are same as those of N212-3b (Table 1). The differences among N212-1d, N212$2 b$, and N212-2c, and between N212-2d and N212-3b are the locations of Pt-black layers. In structure-b MEA, the Ptblack layers are located at the interface between Pt-C layer and GDL; and in structure-c MEA, the Pt-black layers are located at the interface between $\mathrm{Pt}-\mathrm{C}$ layer and membrane. However in structure-d MEA, the Pt-black layers are located both at the interfaces between Pt-C layer and membrane and between Pt-C layer and GDL. Table 7 also shows that the Ptblack loading at cathode is same as that at anode, though the total Pt loading at cathode is twice of that at anode.

Table 6. $\quad a, b, i_{o}$ Values (Eq. 1) of Structure-c MEAs Obtained from Fig. (7)

\begin{tabular}{|c|c|c|c|c|}
\hline MEA\# & $\mathbf{b}\left(\mathbf{m} \boldsymbol{\Omega} \mathbf{~ c m}^{2}\right)$ & $\boldsymbol{\alpha}$ & $\mathbf{a}(\mathbf{V})$ & $\boldsymbol{i}_{\mathbf{0}}\left(\mathbf{m A ~} \mathbf{~ c m}^{-2}\right)$ \\
\hline \hline $\mathrm{N} 212-1 \mathrm{c}$ & 0.1072 & 0.6 & 0.1430 & 0.046 \\
\hline $\mathrm{N} 212-2 \mathrm{c}$ & 0.1002 & 0.7 & 0.1595 & 0.026 \\
\hline
\end{tabular}

Figs. $(8,9)$ show the cell potential $V$ versus $i$ and power density $P D$ versus $i$ curves, respectively, for N212-1d, N212$2 \mathrm{~d}$, and N212-a. Table 8 summarizes the OCV, $\mathrm{PD}_{\max }$, and $R$ values of N212-1d and N212-2d MEAs. The data of Figs. (8, 9) show that N212-1d and N212-2d have better fuel cell performance than $\mathrm{N} 212$-a, indicating replacing $20 \sim 40 \mathrm{wt} . \%$ $\mathrm{Pt}$ of Pt-C (40 wt.\% Pt) with Pt-black at anode and replacing $10 \sim 20$ wt. $\%$ Pt of Pt-C (40 wt.\% Pt) with Pt-black at cathode (N212-1d and N212-2d) and coating Pt-black layer at interfaces between Pt-C layer and GDL and between Pt-C layer and membrane can improve fuel cell performance. These results also show that replacing 20 wt.\% Pt of Pt-C (40 wt.\% Pt) with Pt-black at anode and replacing 10 wt.\% Pt of Pt-C (40 wt.\% Pt) with Pt-black at cathode (i.e. N2121d) has the best fuel cell performance in these MEAs.

Tables 1 and 7 show the thicknesses of N212-1d and N212-2d are lower than that of N212-a, and Tables 2 and 8 also show $\mathrm{N} 212-1 \mathrm{~d}$ and $\mathrm{N} 212-2 \mathrm{~d}$ have lower resistance $R$ than $\mathrm{N} 212$-a at $i=200,400,800$, and $1000 \mathrm{~mA} \mathrm{~cm}^{-2}$. Fig. (10) shows the plots of Eq. 1 for N212-a, N212-1d, and N212-2d. The values of $a, b, i_{o}$, and $\alpha$ calculated from plots of Fig. (10) are listed in Table 9 . Tables 3 and 9 show that N212-a has higher $i_{o}$ than N212-1d and N212-2d, and N212$2 \mathrm{~d}$ has lowest $i_{o}$ in these three MEAs, indicating the catalysts

Table 7. The Catalysts Loadings of Structure-d MEAs. Total Pt Loading is $0.5 \mathrm{mg} \mathrm{cm}$ at and $1.0 \mathrm{mg} \mathrm{cm}$ at Cathode

\begin{tabular}{|c|c|c|c|c|c|c|c|}
\hline \multirow{2}{*}{ MEA\# } & \multicolumn{3}{|c|}{ Anode (mg cm-2 } & \multicolumn{3}{c|}{ Cathode (mg cm $\left.{ }^{-2}\right)$} & MEA Thickness $(\mu$ m) \\
\cline { 2 - 8 } & Pt Near GDL & Pt-C (40 wt.\% Pt) & Pt Near Membr & Pt Near Membr & Pt-C (40 wt.\% Pt) & Pt Near GDL & 0.05 \\
\hline \hline N212-1d & 0.05 & 1.0 & 0.05 & 0.05 & 2.25 & 0.1 & 431 \\
\hline N212-2d & 0.1 & 0.75 & 0.1 & 0.1 & 2.0 & 407 \\
\hline
\end{tabular}


of N212-a have highest specific area $a_{c}$ and those of N212$2 \mathrm{~d}$ have lowest specific area $a_{c}$. These results are also similar to those of N212-a with N212-1b and N212-2b and those of N212-a with N212-1c and N212-2c. Since MEAs N212-a, $\mathrm{N} 212-1 \mathrm{~d}$, and N212-2d have same proton exchange membrane and same amount of total Pt loading, we may also attribute the better fuel cell performance of N212-1d and N212-2d than N212-a to the lower catalyst layer thickness (or shorter proton transport path length) of N212-1d and $\mathrm{N} 212-2 \mathrm{~d}$ than $\mathrm{N} 212-\mathrm{a}$, which leads to lower proton transport resistance of N212-1d and N212-2d than N212-a.

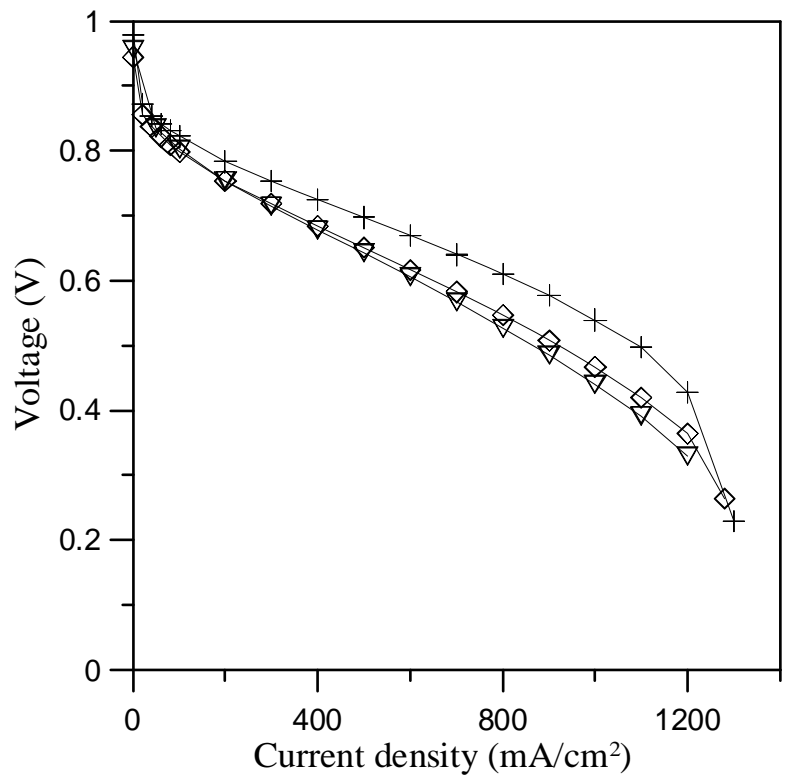

Fig. (8). $i-\mathrm{V}$ curves of structure-a and structure-d single cells operated at $80^{\circ} \mathrm{C}$ with both $\mathrm{H}_{2}$ and $\mathrm{O}_{2}$ flow rates of $200 \mathrm{ml} / \mathrm{min}$. ( $\left.\nabla\right)$ N212-a; (+) N212-1d; (॰) N212-2d.

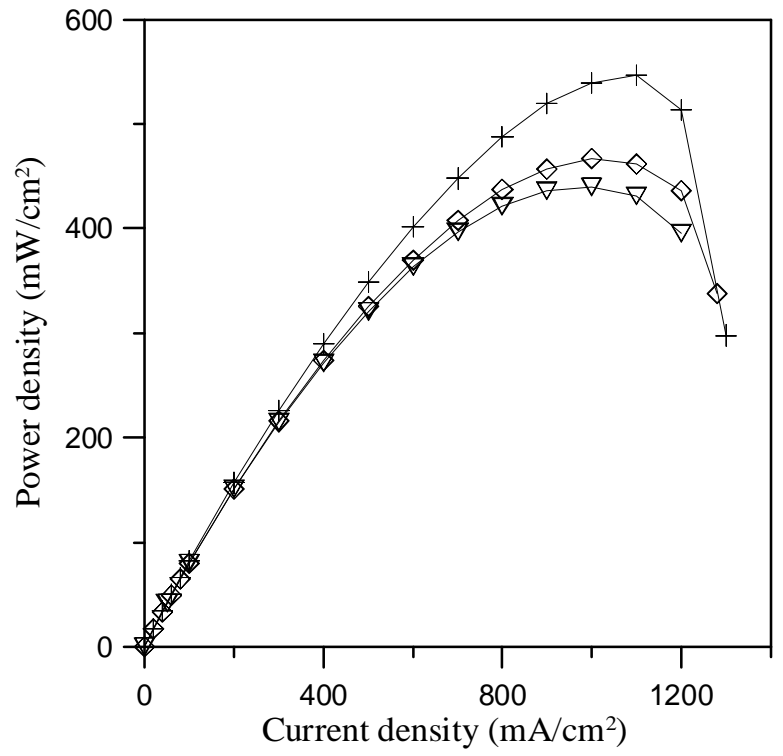

Fig. (9). $i$-PD curves of structure-a and structure-d single cells operated at $80^{\circ} \mathrm{C}$ with both $\mathrm{H}_{2}$ and $\mathrm{O}_{2}$ flow rates of $200 \mathrm{ml} \mathrm{min}^{-1}$. $(\nabla) \mathrm{N} 212-\mathrm{a} ;(+) \mathrm{N} 212-1 \mathrm{~d} ;(\diamond) \mathrm{N} 212-2 \mathrm{~d}$.
Table 8. OCV, $P D_{\max }$, and $R$ Values of Structure-d MEAs

\begin{tabular}{|c|c|c|}
\hline MEA $\#$ & N212-1d & N212-2d \\
\hline \hline OCV $(\mathrm{V})$ & 0.98 & 0.95 \\
\hline $\mathrm{PD}_{\max }\left(\mathrm{mW} \mathrm{cm}{ }^{-2}\right)$ & 554 & 470 \\
\hline$R\left(\Omega \mathrm{cm}^{2}\right)$ at $i=200 \mathrm{~mA} \mathrm{~cm}^{-2}$ & 0.105 & 0.129 \\
\hline$R\left(\Omega \mathrm{cm}^{2}\right)$ at $i=400 \mathrm{~mA} \mathrm{~cm}^{-2}$ & 0.104 & 0.120 \\
\hline$R\left(\Omega \mathrm{cm}^{2}\right)$ at $i=800 \mathrm{~mA} \mathrm{~cm}^{-2}$ & 0.105 & 0.122 \\
\hline$R\left(\Omega \mathrm{cm}^{2}\right)$ at $i=1000 \mathrm{~mA} \mathrm{~cm}^{-2}$ & 0.110 & 0.127 \\
\hline
\end{tabular}

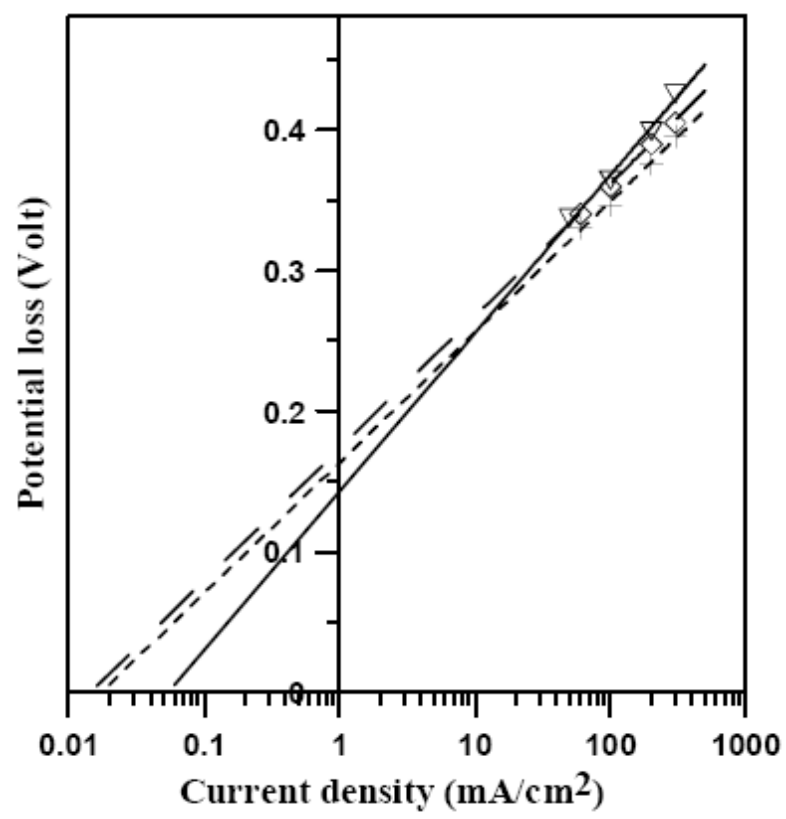

Fig. (10). Plots of activation loss potential $\Delta \mathrm{V}_{\text {act }}$ versus $\log i$ (Eq. 1)of structure-a and structure-d MEAs. ( $\nabla---)$ N212-a; (+--------) N212-1d; (॰- - - ) N212-2d.

Table 9. $a, b, i_{o}$ values (Eq. 1) Obtained from Fig. 13 of Structure-a and Structure-d MEAs

\begin{tabular}{|c|c|c|c|c|}
\hline MEA\# & $\mathbf{B}\left(\mathbf{m} \boldsymbol{\Omega} \mathbf{~ c m}^{2}\right)$ & $\boldsymbol{\alpha}$ & $\mathbf{a}($ Volt $)$ & $\boldsymbol{i}_{\mathbf{0}}\left(\mathbf{m A ~ \mathbf { c m } ^ { - 2 } )}\right.$ \\
\hline \hline $\mathrm{N} 212-1 \mathrm{~d}$ & 0.0928 & 0.8 & 0.1636 & 0.017 \\
\hline $\mathrm{N} 212-2 \mathrm{~d}$ & 0.0941 & 0.7 & 0.1726 & 0.015 \\
\hline
\end{tabular}

\subsection{Comparison of PEMFC Performances of Structure- b, Structure-c, and Structure-d MEAs}

It is interesting to compare the fuel cell performances of MEAs consisting of a fixed Pt loading but with different catalyst layer structures. Tables 1, 4 and 7 show that N2122b, N212-2c, and N212-1d MEAs have same Pt-C and Ptblack loadings at anode and cathode. From Tables 2, 5, and 8 , we found the maximum power densities $P D_{\max }$ of N2122b, N212-2c, and N-212-1d MEAs are $500 \mathrm{~mW} \mathrm{~cm}^{-2}, 550$ $\mathrm{mW} \mathrm{cm} \mathrm{cm}^{-2}$, and $554 \mathrm{~mW} \mathrm{~cm}^{-2}$, respectively. These data show 
that structure-c and structure-d MEAs have much better performances than structure-b MEA. Two reasons of the worse fuel cell performance of structure-b MEA than structure-c and structure-d MEAs are: (1) the nano Pt-black particles layer at the interface of Pt-C and GDL may cause blockage of fuel $\mathrm{H}_{2}$ and oxidant $\mathrm{O}_{2}$ flows in structure-b MEA; (2) the protons produced on the catalysts surfaces of nano Pt-black layer near the membrane of structure-c and structure-d MEAs have shorter proton transport path length than the proton produced on the catalysts surfaces of nano Pt-black layer near GDL of structure-b MEA.

N212-2c and N212-1d MEAs have same Pt-C and Ptblack loadings at anode and cathode. The difference between $\mathrm{N} 212-2 \mathrm{c}$ and N212-1d is the locations of Pt-black layers. In N212-2c MEA, a Pt-black layer with $0.100 \mathrm{mg} \mathrm{cm}^{-2} \mathrm{Pt}$ loading is located at the interface between Pt-C layer and membrane in anode and cathode. In N212-1d MEA, two Ptblack layers (each with $0.050 \mathrm{mg} \mathrm{cm}^{-2} \mathrm{Pt}$ loading) are located separately at interfaces between Pt-C and membrane and between Pt-C and GDL in anode and cathode. In other words, N212-1d is a MEA modified from N212-2c by shifting $0.050 \mathrm{mg} \mathrm{cm}^{-2} \mathrm{Pt}$ loading from the interface between membrane and Pt-C layer to the interface between Pt-C layer and GDL. In the preceding paragraph, we mentioned that performances of MEAs with Pt-black layer locating at the interface between membrane and Pt-C layer (structure-c MEA) are better than those of MEAs with Pt-black layer locating at the interface between Pt-C layer and GDL (structure-b MEA). Therefore, we predict the performance of N212-2c could be better than that of N212-1d. However, the $i$-V curve of N212-2c (Fig. 5) shows voltage of $0.65 \mathrm{~V}, 0.60$ $\mathrm{V}$, and $0.52 \mathrm{~V}$ at $i=500,800$, and $1000 \mathrm{~mA} \mathrm{~cm}^{-2}$, respectively, and the $i-\mathrm{V}$ curve of N212-2d (Fig. 8) shows voltage of $0.67,0.61$, and $0.55 \mathrm{~V}$ at $i=500,800$, and 1000 $\mathrm{mA} \mathrm{cm}{ }^{-2}$, respectively. The data reveals that structure-d MEA has better fuel cell performance than structure-c MEA. The reason that $\mathrm{N} 212-1 \mathrm{~d}$ has better fuel cell performance than N212-2c is still not clear to us. It may be in the range of experimental error.

\section{CONCLUSIONS}

The modified 7-layer and 9-layer MEAs with thin Ptblack catalyst layers located either at the interface between Pt-C layer and GDL or/and at the interface between membrane and Pt-C layer are prepared in the present work. Comparing with the conventional 5-layer MEA, the Pt-C catalyst loading in the Pt-C layer of the modified MEA is reduced and the reduced amount of $\mathrm{Pt}$ loading from $\mathrm{Pt}-\mathrm{C}$ layer is equal to the increased amount of Pt loading at the Ptblack layer. Thus the total Pt loadings of the unmodified conventional 5-layer MEA and of the modified 7-layer and 9-layer MEAs are at a fixed quantity. Though the modified MEAs may complicate the manufacture process, our experimental results show that the 7-layer and 9-layer MEAs have better fuel cell performance than the 5-layer MEA. The experimental results also show that the structure-c MEA with a thin Pt-black layer coated at the interface between membrane and Pt-C layer has a better fuel cell performance than the structure-b MEA with a thin Pt-black layer coated at the interface between the Pt-C and GDL. The main advantage of these 7-layer and 9-layer MEAs is the low thickness of catalyst layer and thus low proton transport resistance in catalyst layer. Because of thin thickness of

Pt-black layer in MEA, we avoid agglomeration of Pt-black particles and maintain high catalytic activity of Pt-black particles. Using these new catalyst layer structure designs, we reduce proton transport resistance in catalyst layer and also maintain high Pt catalytic efficiency. Thus we improve PEM fuel cells performance.

\section{ACKNOWLEDGEMENT}

The authors would like to thank for the financial support by Bureau of Energy, Ministry of Economy Affair of ROC through grants 101-D0204-4.

\section{CONFLICT OF INTEREST}

\author{
Declared none.
}

\section{REFERENCES}

[1] Watanabe, M. In: Handbook of Fuel Cells; Vielstich, W.; Lamm, A.; Gasteiger, H.A., Ed.; John Wiley \& Sons: Chichester, England, 2003; vol. 2., chap. 28; Lasita A. in ibid, chap. 29; Mukerjee, S.; Srinivasan, S., in ibid, chap. 34.

[2] Mehta, V.; Cooper, J.S. Review and analysis of PEM fuel cell design and manufacturing. J. Power Sources, 2003, 114, 32-53.

[3] Wang, Q.; Eikerling, M.; Song, D.; Liu, Z.; Navessin, T.; Xie Z.; Holdcroft, S. Functionally graded cathode catalyst layers for polymer electrolyte fuel cells. J. Electrochem. Soc., 2004, 151(7), A950-A957.

[4] Xie, Z.; Navessin, T.; Shi, K.; Chow, R.; Wang, Q.; Song, D.; Audreaus, B.; Eikerling, M.; Liu, Z.; Holdcroft, S. Functionally graded cathode catalyst layers for polymer electrolyte fuel cells II, experimental study of the effect of nafion distribution. $J$. Electrochem. Soc., 2005, 152(6), A1171-A1179.

[5] Wilson, M.S.; Gottesfeld, S. High performance catalyzed membranes of ultra-low Pt loadings for polymer electrolyte fuel cells. J. Electrochem. Soc., 1992, 139, L28-L30.

[6] Wilson, M.S.; Gottesfeld, S. Thin-film catalyst layers for fuel cell electrodes polymer electrolyte. J. Appl. Electrochem., 1992, 22, 17.

[7] Hirano, S.; Kim, J.; Srinivasan, S. High performance proton exchange membrane fuel cells with sputter-depos. Electrochim. Acta, 1977, 42, 1587-1593.

[8] Cavalcam, C.A.; Arps, J.H.; Murphy, M. Fuel cell membrane electrode assemblies with improved power outputs and poison resistance. U.S. Patent. 63,000,000 B1, Oct 9, 2001.

[9] Lister, S.; McLean, G. PEM fuel cell electrodes. J. Power Sources, 2004, 130, 61-76.

[10] Pierre, J.S.; Wilkinson, D.P.; Campbell, S.A. Method and device for improved catalytic activity in the purification of fluids. U.S. Patent 6,896,792 B2, May. 24, 2005.

[11] Yan, S.G.; Doyle, J.C. Membrane electrode assembly prepared by direct spray of catalyst to membrane. U.S. Patent 0,163,920 A1, Jul $28, \mathbf{2 0 0 5}$

[12] Yan, S.G.; Sompalli, B. Durable membrane electrode assembly catalyst coated diffusion media with no lamination to membrane. U.S. Patent 0,164,072 A1, Jul 28, 2005.

[13] Olmeijer, D. Membrane and membrane electrode assembly with adhesion. U.S. Patent 0,068,268 A1, Mar 30, 2006.

[14] Thompson, S.D.; Jordan, L.R.; Forsyth, M. Platinum electrodeposition for polymer electrolyte membrane fuel cells. Electrochim. Acta, 2001, 46, 1657-1663.

[15] Larminie, J.L.; Dicks, A. Fuel Cells Systems Explained, John Wiley \& Sons: Chichester, England, 2000, p. 6, Fig. (1.6).

[16] Barbir, F. PEM Fuel Cells, Elsevier Academic Press: MA, USA, 2005, chap. 4, p. 90, Table 4.

[17] E-Tek Co website. Available at: http://www.etek-inc.com [Accessed: Apr 19, 2012].

[18] Ticianelli, E.A.; Derouin, C.R.; Srinivasan, S. Localization of platinum in low catalyst loading electrodes to to attain high power densities in SPE fuel cells. J. Electroanal. Chem., 1988, 251, 275295. 
[19] Mukerjee, S.; Srinivasan, S.; Appleby, A.J. Effect of sputtered film of platinum on low platinum loading electrodes on electrode kinetics of oxygen reduction in proton exchange membrane fuel cells. Electrochim. Acta, 1993, 38(12), 1661-1669.

[20] Yang, T.F.; Hourng L.W.; Yu, T.L.; Chi, P.H.; Su, A. High performance proton exchange membrane fuel cell electrode assemblies. J. Power Sources, 2010, 195, 7350-7369.

[21] Grot, W.G.F. Nafion perfluorinated membranes product bulletin. LA, USA: DuPont Polymer Products Department, 1986.
[22] Du Pont Co website. Available at: http://www.dupont.com/fue lcells/en_US/ products/nafion.html [Accessed: Apr. 19, 2012].

[23] Babir, F. PEM Fuel Cells: Theory and Practice, Elsevier Academic Press: Burlington, MA, 2005; Chap. 8.

[24] Babir, F. PEM Fuel Cells: Theory and Practice, Elsevier Academic Press: Burlington, MA, 2005; Chap. 3.

[25] Larminie, J.; Dicks A. Fuel Cell Systems Explained, John Wiley \& Sons: Chichester, England, 2000, Chap. 3

(C) Yu et al.; Licensee Bentham Open.

This is an open access article licensed under the terms of the Creative Commons Attribution Non-Commercial License (http://creativecommons.org/licenses/by$\mathrm{nc} / 3.0 /$ ) which permits unrestricted, non-commercial use, distribution and reproduction in any medium, provided the work is properly cited. 